\title{
Predicting the Bed Height in Expanded Bed Adsorption Column using R-Z Correlation
}

\begin{abstract}
Expanded Bed Adsorption (EBA) enables the protein recovery directly from cultivations of microorganisms or cells and preparations of disrupted cells, without the need for prior removal of suspended solids. The performance of an expanded bed is comparable to a packed bed/fluidized bed. To extend the EBA technology in industries, a better understanding of the expanded-bed behavior is necessary to maximize its efficient applications. In this work the steady state hydrodynamic behaviour of expanded beds particularly bed expansion/ average porosity was studied experimentally. Two models are used to predict the terminal velocity of particles: one is Stokes law and other one is Shiller and Naumann model. The experimental results are in close agreement with the predicted porosity of Stokes law followed by Richardson - Zaki equation than the other model.
\end{abstract}

B.S.V.S.R. Krishna
Keywords--- Expanded Bed Adsorption, Static Bed Height, Expanded Bed Height, Porosity, Hydrodynamics

\section{NOMENCLATURE}

Ar Archimedes number $=\frac{d_{p}^{3} g\left(\rho_{p}-\rho_{l}\right) \rho_{l}}{\mu}$

$\mathrm{d}_{\mathrm{p}}$ diameter of particle, microns, $\mathrm{mm}$

D Diameter of column, $\mathrm{mm}$ or $\mathrm{cm}$

g gravitational constant $9.8 \mathrm{~m} / \mathrm{s}^{2}$

$\mathrm{H}$ settled bed height, $\mathrm{cm}$

$\mathrm{H}_{\mathrm{e}}$ expanded bed height, $\mathrm{cm}$

$\mathrm{n} \mathrm{R}-\mathrm{Z}$ parameter in Eq (1)

$\mathrm{Re}_{\mathrm{t}}$ particle terminal Reynolds number

$\mathrm{u}_{\mathrm{l}}$ liquid velocity, $\mathrm{m} / \mathrm{s}$

$\mathrm{u}_{\mathrm{t}}$ particle terminal velocity, $\mathrm{m} / \mathrm{s}$

Italics

$\varepsilon$ Expanded bed porosity

$\varepsilon_{0}$ Settled bed porosity

$\rho_{\mathrm{l}}$ liquid density, $\mathrm{kg} / \mathrm{m}^{3}$

$\rho_{\mathrm{p}}$ particle density, $\mathrm{kg} / \mathrm{m}^{3}$

$\mu$ viscosity, Pa.s

B.S.V.S.R. Krishna, Associated Professor, Department of Chemical Engineering, MIT, Manipal University, Manipal-576104, India. E-mail: krishna.bandaru@manipal.edu

DOI: 10.9756/BIJIEMS.4727

\section{INTRODUCTION}

בXPANDED BeD ADSORPTION (EBA)" is an - innovative and special chromatography technique for the recovery, separation and purification of target proteins directly from broth. On the other hand, EBA column is a single-unit that combines several unit operation steps such as concentration, centrifugation, micro-filtration and other prior clarification steps than conventional packed bed/fluidized bed chromatography techniques and shown in Figure 1. Advantages of EBA columns are decreasing the time of operation, total production costs, increasing product quality, process yield, etc. [1], [2], [3]. The performance of EBA column is quite complex due to the following factors i.e hydrodynamics of the column, terminal velocity of particle and target component separation. It is fundamental to understand the hydrodynamic characteristics of EBA system [3], [4]. In EBA column, the adsorbent particles that are used should have a wide size/density distribution. At a particular liquid velocity (above minimum fluidization velocity of bigger particles), the particle reaches to hydrodynamic equilibrium due to the forces acting on a single particle that is balanced and it leads to weak particle mixing.

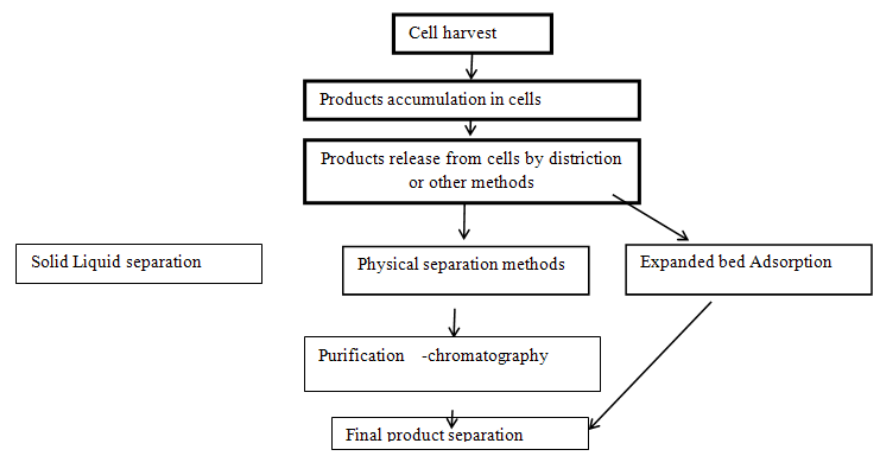

Fig. 1: Process Path Ways with Conventional and EBA

Therefore, particles are classified perfectly and variation of the mean particle size and local bed voidage along the bed height are established in an EBA column. This trend leads to inhomogeneous hydrodynamics and adsorption behavior along the bed.

\section{LITERATURE SURVEY}

Number of experimental and modelling studies performed to identify the axial variation of particle size over the bed height, within an EBA system. Many Researchers [4], [5] employed in-bed liquid and particle sampling procedures to estimate the variation of hydrodynamic behaviour in an EBA system. They found that, classification of the particles occurs and particles with larger size/higher density were located at 
the bottom regions and smaller size/lower density were near, at the top regions of the column. Their experimental results showed that the bed voidage increases with an increase of column height [4], [5]. On the other hand, axial mixing and dispersion are much lower in the top zones than in the bottom zones [5]. Most of the studies performed on Stream line columns rather customized columns to suit the exact requirement. Present authors have studied the hydrodynamic parameters such as bed height and porosity measurements on newly fabricated column to suit the customized dimensions.

\section{A. Average Bed Porosity/Voidage}

"Richardson and Zaki (1954) (R-Z)" [6] explained the correlation between superficial velocity, terminal velocity of particle with bed expansion (Eq. (1)). This correlation has been widely applied for liquid-solid fluidized beds in numerous empirical and semi-empirical studies of average bed expansion. The R-Z correlation was used to measure the average porosity for EBA column [7] and others employed this correlation to measure local bed voidage along the bed height in their classical fluidized bed models [8],[9].

$$
\frac{u_{l}}{u_{t}}=\varepsilon^{n}
$$

where $u_{t}$ is the particle terminal velocity and $n$ is the bed expansion index ( $\mathrm{R}-\mathrm{Z}$ correlation exponent) and $\mathrm{n}$ values are shown Table 1 [10].

\section{B. Terminal Velocity}

Method 1: The particle terminal velocity can be calculated from Stokes Law equation for small particles as shown in Eq. (2)

$$
u_{t}=\frac{d_{p}^{2}\left(\rho_{p}-\rho_{l}\right) g}{18 \mu}
$$

Method 2: The theoretical method of "Shiller and Naumann (1935) (S-N model)" [11] can also be used to predict [12] the particle terminal Reynolds number. The correlation was given below

$$
A r=18 R e_{t}+2.7 R e_{t}^{1.687}
$$

where Ar is Archimedes number

The terminal velocity calculated using Eq (4) as shown below

$$
u_{t}=\frac{R e_{t} \mu}{d_{p} \rho_{l}}
$$

The above two methods were used to calculate the terminal velocity and substituted in Eq (1) of R-Z equation to calculate the average porosity.

Table 1: Values of Parameter $\mathrm{n}$ in R-Z Equation

\begin{tabular}{|l|l|l|}
\hline S. No & $\mathrm{Re}_{\mathrm{t}}$ range & $\mathrm{n}$ \\
\hline 1 & $\mathrm{Re}_{\mathrm{t}}<0.2$ & $4.65+19.5 \mathrm{~d}_{\mathrm{p}} / \mathrm{D}$ \\
\hline 2 & $0.2<\mathrm{Re}_{\mathrm{t}}<1$ & $\left(4.35+17.5 \mathrm{~d}_{\mathrm{p}} / \mathrm{D}\right) \mathrm{Re}_{\mathrm{t}}^{-0.03}$ \\
\hline 3 & $1<\mathrm{Re}_{\mathrm{t}}<200$ & $\left(4.45+18 \mathrm{~d}_{\mathrm{p}} / \mathrm{D}\right) \mathrm{Re}_{\mathrm{t}}^{-0.1}$ \\
\hline 4 & $200<\mathrm{Re}_{\mathrm{t}}<500$ & 4.45 \\
\hline 5 & $\operatorname{Re}_{\mathrm{t}}>500$ & 2.39 \\
\hline
\end{tabular}

\section{EXPERIMENTAL}

\section{A. Materials}

The particles used in this experiment were: particles 1 , particle 2, particle 3 and particle 4 . The physical properties were presented in Table 2 .

Table 2: Physical Properties of the Particles

\begin{tabular}{|l|l|l|}
\hline Particle & Av. size (micron) & Density (g/ml) \\
\hline Particle 1 & 190 & 1.205 \\
\hline Particle 2 & 130 & 1.775 \\
\hline Particle 3 & 70 & 3.150 \\
\hline Particle 4 & 160 & 1.190 \\
\hline
\end{tabular}

The experiments were conducted in a plexi glass column with $19 \mathrm{~mm}$ (internal diameter) and height of $1 \mathrm{~m}$. A mesh was used as a liquid distributor at bottom and another mesh was used as protector at top of the column to prevent the particle carryover. Bed expansion/height was identified visually. All experiments were performed using high purity water. The schematic experimental setup was shown in Fig 2.

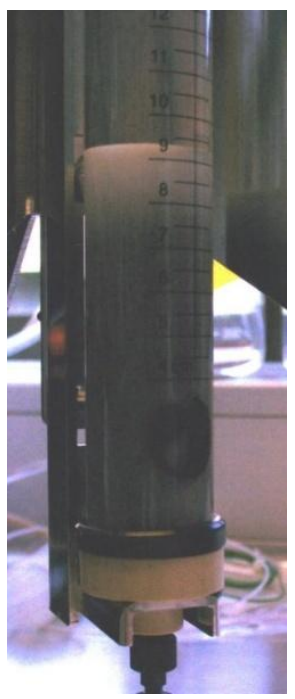

Fig. 2: Schematic Diagram of Experimental

\section{B. Experimental Procedure}

The column was loaded with known amount of solid particles with initial height of 5 (or) $10 \mathrm{~cm}$. The liquid velocity was varied from 3 to $900 \mathrm{~cm} / \mathrm{hr}$. The static bed/settled bed porosity was measured as 0.39 by draining the liquid occupied in the pores for a given volume of bed with following formula.

$$
\varepsilon_{0}=\frac{\text { volume of } \text { water drained }}{\text { total volume of settled bed }}
$$

Table 3: Minimum Fluidization Velocity of Particles using Wen-Yu Equation

\begin{tabular}{|l|l|}
\hline Particle & $\mathrm{u}_{\mathrm{mf}}$ (average), $\mathrm{m} / \mathrm{s}$ \\
\hline Particle 1 & 0.00897 \\
\hline Particle 2 & 0.01143 \\
\hline Particle 3 & 0.00474 \\
\hline Particle 4 & 0.00533 \\
\hline
\end{tabular}


The velocities used in the experiments were above minimum fluidization velocity and calculated using Wen $-\mathrm{Yu}$ equation [13] with average particle diameter and tabulated in Table 3.

\section{RESULTS AND DISCUSSION}

\section{A. Expanded Bed Height}

The dependency of steady state bed height on superficial liquid velocity is plotted in Fig. 3 .

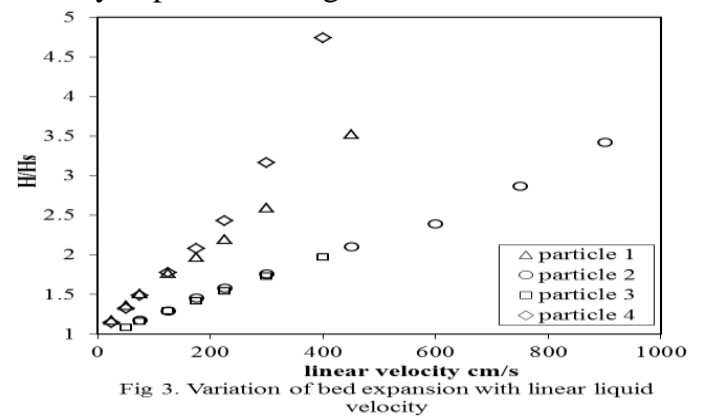

It can be seen from the Figure that bed gradually expands with superficial liquid velocity and reaches to the top of the column further the particles elutriates. The elutriation can be prevented by the top adaptor.

\section{B. Porosity}

The voidage/porosity of expanded bed is measured using the Eq.(4)

$$
\varepsilon=\left(1-\varepsilon_{0}\right) H / H_{e}
$$

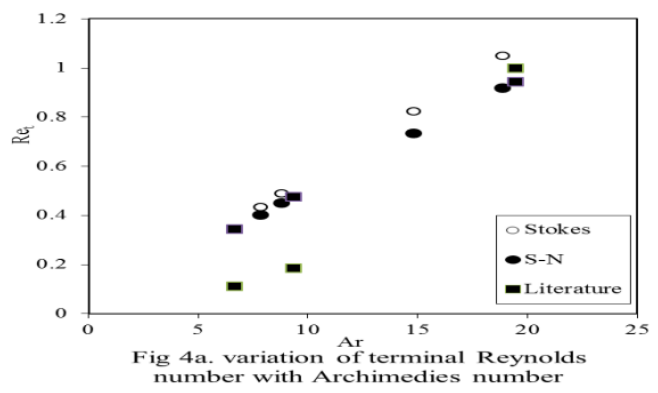

Figure $4 \mathrm{a}$ shows the variation of calculated terminal Reynolds number with Archimedes number. From the Fig 4a, one can identify that terminal Reynolds number increases with Archimedes number. This is in agreement with Literature. Figure $4 \mathrm{~b}$ shows variation of Experimental average porosity with liquid velocity. The average porosity increases with increasing liquid velocity.

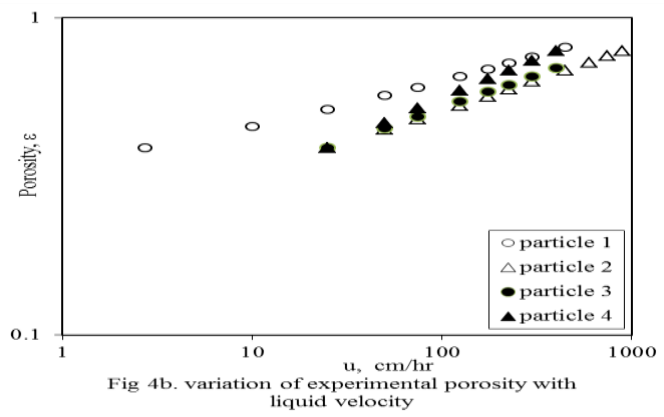

\section{Prediction of Porosity}

Present authors used two methods to predict the expanded bed porosity. 1) Use of Stokes law equation to calculate the terminal velocity and followed by the $\mathrm{R}-\mathrm{Z}$ equation to calculate the average porosity. 2) Use of S-N Model to predict the terminal velocity and followed by $\mathrm{R}-\mathrm{Z}$ equation to calculate the averaged porosity. The calculated terminal velocities of the above models are sown in Table 4. The predicted/calculated values of the porosity are shown in Figure $5 \mathrm{a}$ and $5 \mathrm{~b}$ respectively along with Literature data [12],[14],[15]. The literature data is in agreement with prediction data.

Table 4: Particle Terminal Velocity

\begin{tabular}{|l|l|l|}
\hline Particle & $\mathrm{u}_{\mathrm{t}}$ (Stokes law) $\mathrm{m} / \mathrm{s}$ & $\begin{array}{l}\mathrm{u}_{\mathrm{t}} \quad \text { (Shiller and } \\
\text { Naumann) } \mathrm{m} / \mathrm{s}\end{array}$ \\
\hline Particle 1 & 0.0042 & 0.00374 \\
\hline Particle 2 & 0.00783 & 0.00686 \\
\hline Particle 3 & 0.0061 & 0.00564 \\
\hline Particle 4 & 0.00297 & 0.00273 \\
\hline
\end{tabular}
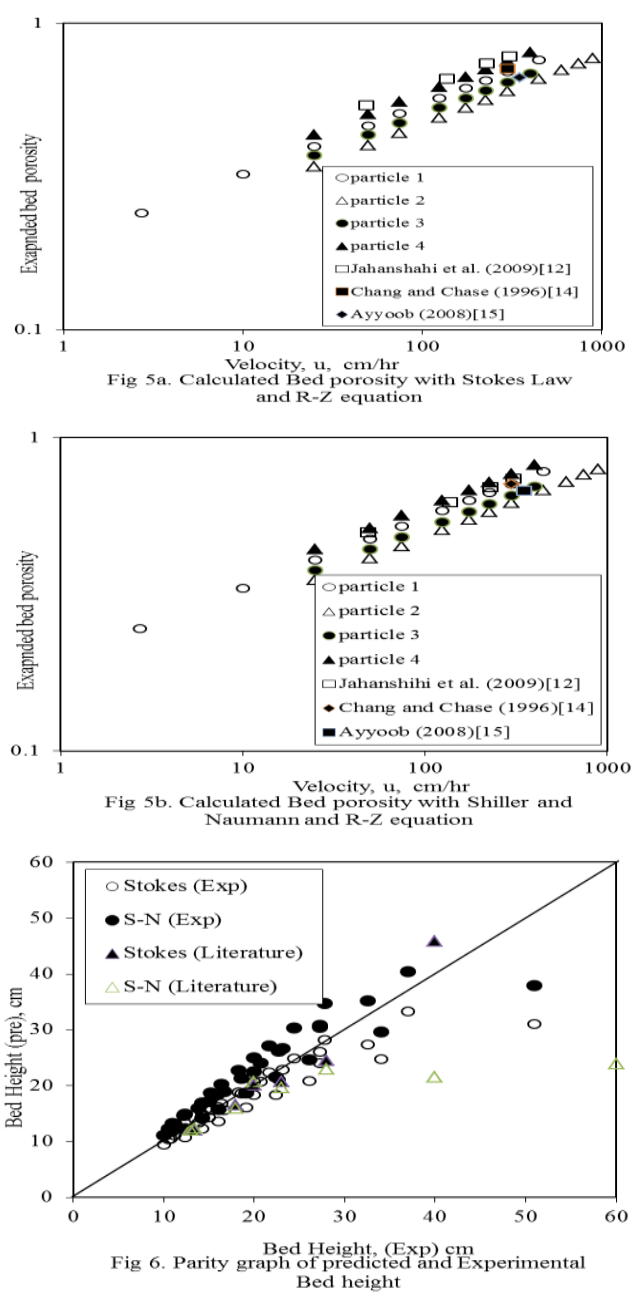

Figure 6 shows the parity plot of predicted expanded bed height using the above two models. The predicted expanded bed height using Stokes equation is in good agreement with experimental bed height with Root Mean Square (RMS) error of $11.4 \%$ than the other model of S-N (16.6\%) for the present Authors experimental data. While including Literature data the 
RMS Error was increased further from $16.6 \%$ to $19.3 \%$ to the $\mathrm{S}-\mathrm{N}$ model but the Stokes equation predicted with same RMS error.

\section{CONCLUSION}

The experiments on Expanded Bed Adsorption column are conducted to predict the average bed porosity or expanded bed height with four types of particles with a customised column. The following conclusions have been drawn from the study.

1) Bed Height and average bed porosity increased with increase in liquid velocity for all particles.

2) The increase in bed height was more for particles 3 and 4 than particle 1 and 2 for given liquid velocity due to the lower Ar for $3 \& 4$.

3) Two models tested to predict the expanded bed porosity.

4) Stokes law followed by R-Z equation predicted better with an RMS error of $11.4 \%$ for experimental and literature data than the S-N Model.

\section{ACKNOWLEDGEMENT}

The Author would like to thank his family (Kavitha T.C. and Lochana K.B.) for their support and help during the work.

\section{REFERENCES}

[1] L.M. Pinotti, L.P. Fonseca, D.M.F. Prazeres, D.S. Rodrigues, E.R. Nucci, and R.L.C. Giordano, "Recovery and partial purification of penicillin $\mathrm{G}$ acylase from E. coli homogenate and B. megaterium culture medium using an expanded bed adsorption column" Biochem. Eng. J., Vol. 44, Pp. 111-118, 2009.

[2] M.Y.T. Ng, W.S. Tan, N. Abdullah, T.C. Ling and B.T. Tey, "Direct purification of recombinant hepatitis B core antigen from two different preconditioned unclarified Escherichia coli feed stocks via expanded bed adsorption chromatography". J. Chromatogr. A, Vol. 1172, Pp. 4756, 2007.

[3] X.D. Tong and Y. Sun, "Particle size and density distributions of two dense matrices in an expended bed system". J. Chromatogr. A, Vol. 977, Pp. 173-183 2002.

[4] B.S.V.S.R. Krishna, L.C. Kessler, M.W. Wolf, U. Reichl A.S. Morgenstern and S. Pushpavanam "Hydrodynamic Characteristics and Expansion Behavior of Beds Containing Single and Binary Mixture of Particles”, Ind. Eng. Chem. Res., Vol. 46, Pp. 4686, 2007.

[5] L.J. Bruce and H.A. Chase, "Hydrodynamics and adsorption behavior within an expanded bed adsorption column studied using in-bed sampling“, Chem. Eng. Sci., Vol. 56, Pp. 3149-3162, 2001.

[6] J.F. Richardson and W.N. Zaki, "Sedimentation and fluidization: Part I" Trans. Inst. Chem. Eng., Vol. 32, Pp. 35-53, 1954

[7] E.S. Taheri, M. Jahanshahi, M.T.H. Mosavian and M.H. Shahavi, "Investigation of Hydrodynamic parameters in a novel Expanded Bed configuration: Local axial dispersion configuration and an empirical correlation study", Brazilian Jr. of Chem. Engg., Vol. 29, I.4, Pp. 725739, 2012.

[8] M.R. Al-Dibouni and J. Garside, "Particle mixing and classification in liquid fluidized beds", Trans. Inst. Chem. Eng., Vol. 57, Pp. 94-103, 1979.

[9] J. Yun, S.J. Yao, D.Q. Lin, M.H. Lu, and W.T. Zhao, "Modelling axial distributions of adsorbent particle size and local voidage in expanded bed”. Chem. Eng. Sci., Vol. 59, Pp. 449-457, 2004.

[10] R.D. Felice and R. Kehlenbeck, "Sedimentation Velocity of Solids in Finite Size Vessels", Chem. Engg. Tech., Vol. 23, No. 12, Pp. 11231126, 2000.

[11] L. Schiller, Z. Naumann and Z Ver. Deutsh. Ing., Vol. 77, Pp. 318, 1935.

[12] M. Jahanshahi, A.A. Ghoreishi, F.F. Vasheghani, M. Khavarpour and A. Abedijaber "Comparative Study of Hydrodynamic behaviour of Liquid Expanded Bed Adsorption: Mathematical and Short cut methods", Brazilian Jr. of Chem. Engg., Vol. 26, No. 2, Pp. 299-306, 2009.
[13] C.Y. Wen and Y.H. Yu, "Mechanics of fluidization", Chem. Engg. Prog. Symp Series, Vol. 62, No. 62, Pp. 100-111, 1966.

[14] Y.K. Chang and H.A. Chase, "Development of Operating Conditions for Protein Purification Using Expanded Bed Techniques: The Effect of the Degree of Bed Expansion on Adsorption Performance", BioTech. and Bio Engg. Vol. 49, Pp. 512-526, 1996.

[15] A. Ayyoob, "Improved Expanded Bed Adsorption Chromatography Systems", PhD Thesis, Biocentrum-DTU, technical University of Denmark, 2008.

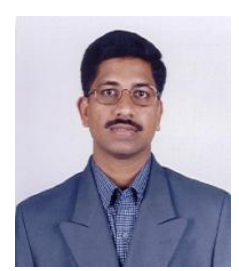

The Author is a committed faculty in Chemical Engineering with 10 years of experience in Academic and Industry. He has authored 12 papers in International Journals and presented 14 papers in International conferences. $\mathrm{He}$ has worked in International project at Germany. 